\title{
Yield, Quality and Water Consumption of Stevia rebaudiana Bertoni Grown under Different Irrigation Regimes in Southern Italy
}

\author{
Antonella Lavini ${ }^{*}$, Maria Riccardi ${ }^{1}$, Cataldo Pulvento ${ }^{1}$, Sergio De Luca ${ }^{1}$, \\ Michela Scamosci ${ }^{2}$, Riccardo d'Andria ${ }^{1}$ \\ ${ }^{1}$ CNR - Institute for Mediterranean Agriculture and Forest Systems (ISAFoM) \\ Via Patacca 85, 80056 Ercolano (NA), Italy \\ ${ }^{2} \mathrm{CNR}$ - Institute for Mediterranean Agriculture and Forest Systems (ISAFoM) \\ Via Madonna Alta 128, 06128 Perugia, Italy
}

Received: 14 January 2008. Accepted: 25 September 2008.

\begin{abstract}
Stevia rebaudiana Bertoni is a herbaceous perennial plant originating in the north-east of Paraguay. Its leaves contain low-calorie sweetening agents that can be used as a natural alternative to artificial sweeteners. The leaves are consumed in special human diets and for the treatment of various diseases. The aim of the present work is to study water consumption, yield potential and quality characteristics of this species under different irrigation levels in southern Italy. The field work was carried out in 2006-2007. Irrigation treatments consisted of a control (T100), irrigated with $100 \%$ restitution of water consumption and two treatments that received a water depth of $33 \%$ (T33) and $66 \%$ (T66) of treatment T100. Watering volume was estimated to replenish the soil profile to field capacity for a depth of $0.40 \mathrm{~m}$. The crop was harvested twice a year, and agronomic performance as well as the major cation and glycoside contents (stevioside and rebaudioside A) were evaluated. Overall, the crop coefficients were similar between the two years, although in each year the second growing period showed higher values due to the higher evaporative demand of this period. Interactions of years with irrigation treatments and harvest time were not significant either for yield or yield components. In both cuts the T100 treatments achieved $40 \%$ higher leaf dry yield than T33, while T66 showed intermediate values. The harvest index and water use efficiency showed no differences between the two cuts for the same treatments, while the values of both indices decreased with the increase in irrigation regime. Stevioside, rebaudioside A and cation content in the leaves were unaffected by irrigation regime. In order to develop the field cultivation of this species, field experiments are required to prepare a cultivation protocol as well as a genetic improvement program to develop varieties that better respond to the local environment.
\end{abstract}

Key-words: irrigation regime, water consumption, crop coefficient, water use efficiency, extract content, yield.

\section{Introduction}

Stevia rebaudiana Bertoni originated in the Rio Monday valley, an area in north-eastern Paraguay (Soejarto et al., 1982). In 1887 this species was described by M.S. Bertoni who named the plant Eupatorium rebaudianum in memory of the Paraguayan chemist Rebaudi, who was the first scientist to study its chemical properties (Midmore and Rank, 2002; Brandle et al., 1992; Andolfi et al., 2006).

In its native area the leaves are traditional- ly used as sweeteners by local Indians (Guaranì) to sweeten infusions (mate) and other beverages or unpalatable medicine (Midmore and Rank, 2002). Although more than 150 species of stevia are currently described, rebaudiana Bertoni is the only one with significant sweetening properties (Soejarto et al., 1982). The species was imported into Europe in the 16th century after the Spanish conquest of South America, but the first studies started in the United Kingdom in the mid 20th century.

To date, although its cultivation has spread

\footnotetext{
* Corresponging Author: Tel. +39 081 7717325; Fax: +39 081 7718045. E-mail address: a.lavini@isafom.cnr.it
} 
to many countries such as Brazil, Korea, Mexico, the United States, Indonesia, Tanzania and Canada, stevia is mainly produced in China. Sumida (1968) began studies aimed to introduce this species into Japan, which has become its largest market (Brandle et al., 1992).

Stevia rebaudiana Bert. (Fam. Asteraceae) in its native area is a herbaceous polyannual plant, while at higher latitudes its cultivation is annual (Goettemoeller and Ching, 1999). Plants are characterized by many branches and at full growth it can reach $0.60-0.80 \mathrm{~m}$ high. The root system is taproot in the first development phases, then becoming a diffuse system since new adventitious roots start to grow from the collar (Brandle et al., 1992; Andolfi et al., 2002). The leaves are elliptic-lanceolate with dentate margins and short stems. The flowers are small (7$15 \mathrm{~mm}$ ), white and collected in small corymbs of 2-6 florets. Seeds are contained in slender achenes of about $3 \mathrm{~mm}$ length with about 20 persistent pappus bristles (Goettemoeller and Ching, 1999; Brandle et al., 1992).

The stevia is a short day species and its growth starts to decrease below $20{ }^{\circ} \mathrm{C}$ (Brandle et al., 1992) while, with a period of 16-h of light the vegetative phase is longer and the level of glycosides increases thanks to a longer accumulation period (Midmore and Rank, 2002).

The sweetness of stevia leaves is given by different diterpenoid steviol-glycosides (Bondarev et al., 2003/2004). The two sweetest glycosides are stevioside (4-13\% of leaf dry weight) and rebaudioside A (2-4\% of leaf dry weight), while concentration of rebaudioside $\mathrm{C}$ and dulcoside $\mathrm{A}$ are about $1-2 \%$ and $0.3 \%$, respectively (Andolfi et al., 2006; Midmore and Rank, 2002). The highest total content of these compounds is present in the leaves, while in flowers and stems such content is $7-8$ and $12-13$ fold lower, respectively. In seeds the amount of the glycosides was 2-2.5 times lower than in flowers, whereas the lowest content is in the roots $(0.1 \%$ of root dry matter). Of the two major compounds the stevioside is prevalent in flowers and seeds, while in stems and roots the proportion between stevioside and rebaudioside A is equal. The glycoside proportion and quantity in leaves is not stable, depending on plant age and on the development phase. Indeed, in young leaves the glycoside content is higher than in mature leaves (Goettemoeller and Ching, 1999;
Bondarev et al., 2003/04; Zaidan et al., 1980).

Stevioside makes up most of the sweetener (60-70\% of the total) and is reported as being $110-270$ times sweeter than sugar. This compound is also responsible for the astringent taste (liquorice taste). Rebaudioside A represents 30$40 \%$ of total sweetener and has the sweetest taste, estimated to be 180-400 times sweeter than sugar with no after-taste. Hence the rebaudioside A / stevioside ratio may give a qualitative measure of sweetness.

The leaves also contain other minor glycosides, including flavonoid glycosides, coumarins, cinnamic acids, phenylpropanoids and some essential oils, but at 30-80 times sweeter than sugar they are in fact less sweet (Midmore and Rank, 2002).

The plant leaves can be used in different forms as fresh, dry, in powder or liquid concentrated. Furthermore, many industrial extractions and purification techniques are available.

Stevia glycosides have no calories and can be used similarly to artificial sweeteners like aspartame. In addition, the sweetener products of stevia are also stable at temperatures up to 200 ${ }^{\circ} \mathrm{C}$, are acid-stable and do not ferment, making them suitable for a wide range of food products including baked/cooked foods.

Besides its sweetening properties, stevia can be used for its hypotensive regulation and antiglycemic activity to treat several diseases, and is thus appropriate in a diabetic diet (Jeppesen et al., 2000). In addition, stevia inhibits bacteria reproduction so it has beneficial effect in dental cavities (Midmore and Rank, 2002); stevia extracts also contribute to improve digestion and gastrointestinal functions (Kinghorn and Soejarto, 1991), while other medical properties are also recognized (Oliveira-Filho et al., 1986; Akashi and Yokoyama, 1975).

Water consumption of this species has been reported for controlled environments or in native areas, although no data are available for southern Italy. Andolfi et al. (2006), reported a poly-annual experiment on agronomic adaptability of this crop in a central-north area of Italy. The authors concluded that although stevia responded well to the pedo-climatic environment, crop water requirements and water consumption were not studied. However, the same authors hypothesized that the crop, with a complete restitution of water requirements, 
could achieve more than one harvest per year.

The aim of the present work is to assess changes induced by different irrigation levels on yield potential, water consumption and quality characteristics of this species grown in the open field in southern Italy.

\section{Materials and methods}

The field trial was conducted in 2006 and 2007 at the CNR - Institute for Agricultural and Forest Mediterranean Systems (ISAFoM) research station located in the Volturno river plain (14 $50^{\prime}$ E, $40^{\circ} 07^{\prime} \mathrm{N}$; $25 \mathrm{~m}$ above sea level), an irrigated area of southern Italy (Tab. 1).

Experimentation involved one genotype of Stevia rebaudiana Bert. Plants were propagated by cuttings in a private nursery from mother plants originating from Paraguay. Healthy and homogeneous rooted cuttings were delivered by the producer in $\Phi 90 \mathrm{~mm}$ pots at the four-leaf stage. The crop was transplanted on 20 April 2006 at a density of 5 plants $\mathrm{m}^{-2}(0.6 \mathrm{~m}$ row spacing). The conventionally tilled $15 \mathrm{~m}^{2}$ plots ( 3 by $5 \mathrm{~m}$ ) received an application of 150, 120 and 100 $\mathrm{kg} \mathrm{ha}^{-1}$ of $\mathrm{N}, \mathrm{P}$ and $\mathrm{K}$ respectively in both years. The $\mathrm{N}$ amount was divided into two equal parts supplied at planting and after the first cutting in both experimental years, whereas $\mathrm{P}$ and $\mathrm{K}$ were distributed at planting and before crop resumption in the second year.

Before planting, soil treatment with oxamyl was applied to control nematodes and ground insects. Weeds were successfully controlled with inter-row cultivation throughout the growing cy-

Table 1. Main soil characteristics of the experimental site.

\begin{tabular}{|c|c|}
\hline \multicolumn{2}{|c|}{ Physical } \\
\hline Classification (a) & Mollic Haplaquet \\
\hline Texture & Sandy Clay \\
\hline Field Capacity (b) & 32.22 \\
\hline Wilting point ${ }^{(b)}$ & 22.11 \\
\hline Bulk density $\left(\mathrm{t} \mathrm{m}^{-1}\right)$ & 1.36 \\
\hline \multicolumn{2}{|c|}{ Chemical } \\
\hline $\mathrm{pH}$ & 7.18 \\
\hline Active $\mathrm{CaCO}_{3}\left(\mathrm{~g} \mathrm{~kg}^{-1}\right)$ & 5.1 \\
\hline Organic Matter $\left(\mathrm{g} \mathrm{kg}^{-1}\right)$ & 13.1 \\
\hline Total N $\left(\mathrm{g} \mathrm{kg}^{-1}\right)^{(\mathrm{c})}$ & 0.18 \\
\hline Exchangeable K (meq $100 \mathrm{~g}^{-1}$ ) & 0.35 \\
\hline
\end{tabular}

\footnotetext{
(a) Soil survey Staff.

(b) Percentage of oven-dried weight

(c) Kjeldahl method.
}

cle. At planting and seven days after planting, plots were equally irrigated to guarantee uniform plant development. Thereafter irrigation level differentiation started.

Treatments consisted of three irrigation regimes in a randomized complete block design with three replicates. Three water regimes were tested: the control (T100), which received the $100 \%$ of the soil water consumption and two deficit irrigation treatments that received a water depth of $66 \%$ (T66) and 33\% (T33) of treatment T100. The irrigation water was distributed weekly using a localized system with on-line drip nozzles delivering $4 \mathrm{~L} \mathrm{~h}^{-1}$ set in a line along the rows at a distance of $0.15 \mathrm{~m}$ from the plants. Watering volume was estimated to replenish the soil profile to field capacity to a depth of 0.40 m. Crop evapotranspiration (ETc) was estimated using the soil water balance method and soil water content was gravimetrically measured for a soil layer of $0-0.60 \mathrm{~m}$ with $0.20 \mathrm{~m}$ increments. To compute the crop water budget, soil water content of each treatment was monitored before and 24-h after each watering and at the beginning and end of growing season. During the crop cycle rainfall exceeding $5 \mathrm{~mm}$ within a 24$h$ period was considered to be significant in the water balance and calculated in the soil water budget under the hypothesis of negligible surface runoff and deep drainage.

The plants of the whole plots were harvested manually twice a year, leaving $0.08-0.01 \mathrm{~m}$ stem height from the collar (Megeji et al., 2005): at DOY 204 and 269 in 2006 and at DOY 210 and 267 in 2007. Each harvest was made at the beginning of flowering. At each cut, leaf area was measured by averaging 2 plants of each elementary plot using a video camera system (Delta - T Image Analysis System Mod. DIAS II, Cambridge, UK) and, on 25 plants per plot, height, fresh weight and dry mass accumulation (stems and leaves) was determined by drying samples in an oven at $60{ }^{\circ} \mathrm{C}$.

Samples for analytical determination (glycosides and cations) were taken from two harvested plants of each elementary plot at harvest. Stevioside and rebaudioside A content were determined on samples taken from all leaves and stems, dried and ground separately from the two plants. The data represent the overall glycoside content of the two parts of the whole plant. Analysis of glycoside content was performed on 
$1 \mathrm{~g}$ dry samples placed in 250-mL Erlenmeyer flasks and extracted by shaking for $30 \mathrm{~min}$ with $100 \mathrm{~mL}$ of $\mathrm{EtOH} 70 \%(\mathrm{w} / \mathrm{w})$ in a $70{ }^{\circ} \mathrm{C}$ water bath. After cooling, a $10-\mathrm{mL}$ aliquot was filtered with filter paper and syringe filter (nylon 0.45 $\mu \mathrm{m})$. Then $10 \mu \mathrm{L}$ were analyzed by HPLC (Varian 9010 with Perkin Elmer LC 90 bio with a SUPELCOSIL LC-NH2 - $5 \mu \mathrm{m} ; 25$ x $4.6 \mathrm{~cm}$ column). To optimize the separation of stevioside and rebaudioside $\mathrm{A}$, an isocratic elution with acetonitrile/water $87: 13,(\mathrm{v} / \mathrm{v})$ for 10 minutes with a flow rate of $2 \mathrm{~mL} \mathrm{~min}^{-1}$; wavelength of UV detector $(210 \mathrm{~nm})$ was adopted. The compounds in each sample were identified by comparing their retention times with those of the standards (stevioside from Extrasynthese, France; rebaudioside A from Wako Chemicals GmbH, Germany) and quantified by calibration curves ( 0 to $2000 \mathrm{mg} / \mathrm{L}$ ). The results are reported as percent of dry weight content (Kolb et al., 2001).

Moreover, the main elements (Fe, $\mathrm{Mn}, \mathrm{Cr}$, $\mathrm{Mg}, \mathrm{Na}, \mathrm{Ca}, \mathrm{K})$ of dried leaves were determined by inductively coupled plasma atomic emission spectrometry (ICP-AES). Leaf samples (0.5 g) were digested with $6 \mathrm{~mL}$ of nitric acid $67 \%(\mathrm{p} / \mathrm{v}$, Suprapur-Merck), $0.2 \mathrm{~mL}$ of hydrofluoric acid $40 \%$ (p/v, Suprapur-Merck) and $2 \mathrm{~mL} \mathrm{H}_{2} \mathrm{O}_{2}$ $30 \%(\mathrm{p} / \mathrm{v}$, Suprapur-Merck) in a microwave digestion system (Milestone MLS-1200 Mega). In order to gauge the effectiveness of the digestion procedure, Polish Certified Reference Material for multielement trace analysis (Oriental Tobacco Leaves CTA-OTL-1) was used, prepared from ICHTJ (Instytut Chemii i Techniki Jadrowej). Digestion was made by adopting the optimized parameters (temperature and power/time steps) suggested by Bettinelli et al. (1996). The decomposed samples were diluted to obtain a final volume of $25 \mathrm{~mL}$. Standard solutions were used for ICP-AES calibration.

Data were analyzed by the analysis of variance (ANOVA) using the SAS (SAS Institute inc., Cary, N.C.) statistical package, and means were compared using Least Significant Difference (LSD) at 0.05 level.

\section{Results and discussion}

\subsection{Climatic conditions and water consumption}

Environmental conditions were typical of a subhumid Mediterranean area (736 $\mathrm{mm}$ precipita-
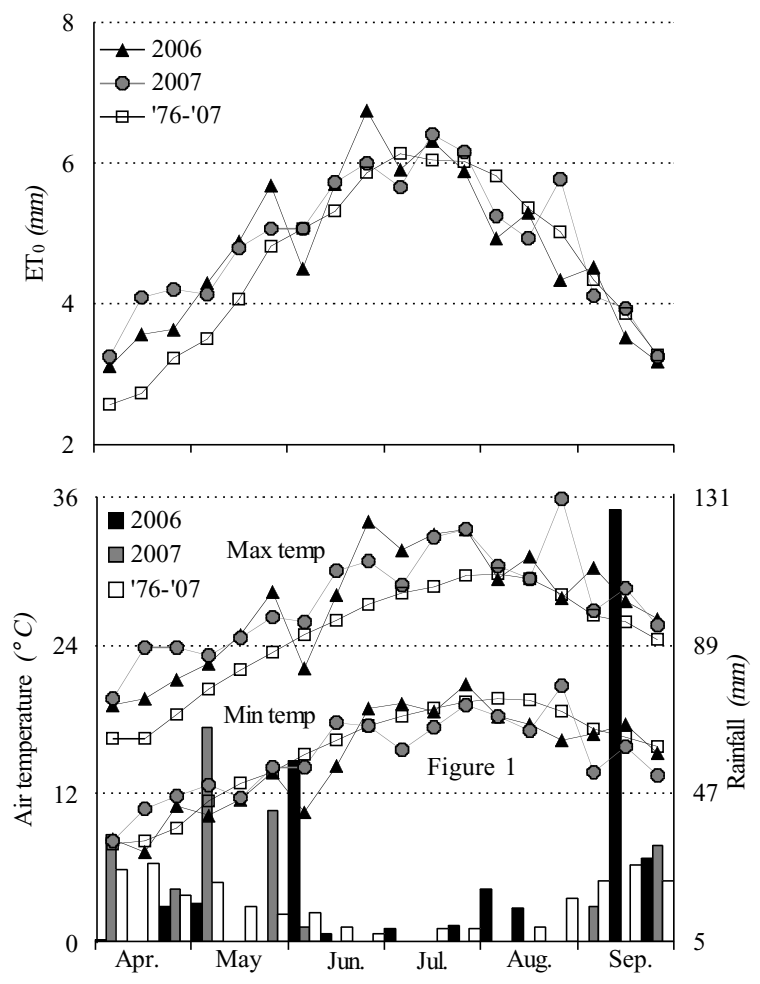

Figure 1. Time course of some climatic parameters in the two experimental years ('06-'07) compared with 32-yr means. Min. and max air temperature are 10-d mean; rainfall is $10-\mathrm{d}$ sum; $\mathrm{ET}_{0}$, estimated according to the HargreavesSamani model, is $10-\mathrm{d}$ mean.

tion - 32-year mean) with scarce precipitation during the summer which did not balance the high summer reference evapotranspiration $\left(\mathrm{ET}_{0}\right)$. Mean daily air temperature increases from 10 - to $12{ }^{\circ} \mathrm{C}$ in April to 24 to $25^{\circ} \mathrm{C}$ at the end of July, and then decreases to $18{ }^{\circ} \mathrm{C}$ in September, while global radiation and vapor pressure deficit (VPD) peaked in July. $\mathrm{ET}_{0}$, calculated using the Hargreaves-Samani model, is about $1132 \mathrm{~mm}$ a year (32-year mean) and increases from about $3 \mathrm{~mm} \mathrm{~d}^{-1}$ in April to about $6 \mathrm{~mm} \mathrm{~d}^{-1}$ in July, and then starts to decrease from the beginning of August (Fig. 1). In June and July the maximum air temperature of both years was generally higher than the polyannual mean value while, in the same period, the minimum temperature was near the 32-year mean. In the first year rainfall amounted to $56.2 \mathrm{~mm}$ in the first decade of June and than little rainfall was monitored until the end of the crop growing season with the exception of a 127.4 $\mathrm{mm}$ event in the second decade of September. 
Table 2. Irrigation volume, seasonal water volume, water consumption, ETo (Hargreaves-Samani model) and computed kc for the whole irrigation season (Irr. season) and for the two growing periods of each experimental year.

\begin{tabular}{|c|c|c|c|c|c|c|c|c|c|c|c|c|c|}
\hline \multirow[t]{2}{*}{ Period } & \multicolumn{3}{|c|}{ Irrigation volume } & \multicolumn{3}{|c|}{ Water volume } & \multicolumn{4}{|c|}{ Water consumption } & \multicolumn{3}{|c|}{$\mathrm{kc}$} \\
\hline & $\mathrm{T} 100$ & T66 & T33 & T100 & T66 & $\mathrm{T} 33$ & $\mathrm{~T} 100$ & T66 & T33 & ETo & $\mathrm{T} 100$ & T66 & $\mathrm{T} 33$ \\
\hline$D O Y$ & & & & & & $m$ & & & & & & & \\
\hline Irr. season '06 & 522 & 344 & 172 & 603 & 426 & 254 & 606 & 417 & 229 & 5.26 & 0.97 & 0.67 & 0.37 \\
\hline $141-204$ & 280 & 185 & 93 & 312 & 217 & 124 & 310 & 200 & 114 & 5.82 & 0.85 & 0.55 & 0.31 \\
\hline $204-262$ & 241 & 159 & 80 & 291 & 209 & 130 & 296 & 217 & 114 & 4.70 & 1.08 & 0.80 & 0.42 \\
\hline Irr. season '07 & 550 & 363 & 182 & 615 & 428 & 247 & 623 & 423 & 252 & 5.32 & 1.02 & 0.67 & 0.39 \\
\hline $142-210$ & 299 & 197 & 99 & 354 & 252 & 154 & 350 & 260 & 168 & 5.74 & 0.90 & 0.67 & 0.43 \\
\hline $210-259$ & 251 & 166 & 83 & 261 & 176 & 93 & 273 & 163 & 84 & 4.9 & 1.14 & 0.68 & 0.35 \\
\hline
\end{tabular}

The latter was not accounted for in the water budget since it occurred after the second harvest. The second year was drier than the first, since the only useful ( $>5 \mathrm{~mm}$ within 24 -h) rain was monitored at crop resumption, while no precipitation occurred from mid June to the beginning of September.

Climatic conditions, as expected, influenced seasonal irrigation amounts in both years. However, in the second year irrigation volumes were $28 \mathrm{~mm}$ higher than in 2006 (522 $\mathrm{mm}$ in 2006 vs. $550 \mathrm{~mm}$ in 2007) in the most irrigated treatment (Tab. 2), while for the other two treatments differences were less evident due to the reduction in the irrigation regime. Water consumption (Tab. 2) was divided into two growing periods: 1) from the beginning of the irrigation to the first harvest, 2) from the first harvest to the last watering. The first growing period was the same in terms of days between the two years, but the second was shorter in 2007, since the high temperature peaks recorded in August probably contributed to shortening the period of growth.

Whole-season water consumption (Tab. 2) reflected the behavior of seasonal water volumes and differences, among the years, were negligible. Indeed, treatments T100, T66 and T33 in the second year consumed only 16.9, 5.3 and $23.5 \mathrm{~mm}$, respectively, more than the same treatments in the first year. According to seasonal water supply, T66 and T33 consumed about 30 and $70 \%$ less water than the control (T100).

The crop coefficient $(\mathrm{kc})$ values, calculated as the ratio between daily water consumption and mean reference ET, were generally similar between the two years. Within the two growing periods kc values of treatments T100 and T66 showed an increase in the second period, while this behavior was detected only in the first year for treatment T33. This tendency was due to the high evaporative demand in the period that occurred from the first to the second harvest.

The kc of treatment T100 were similar to those reported by Gonzales (2000, cited by Fronza and Folegatti 2003) for the native environment of the species, while the values were slightly lower than those reported by Fronza and Folegatti (2003) in an experiment carried out using a lysimeter.

\subsection{Vegetative development and yield}

As three- and two-way interactions of years with irrigation levels and harvest time were not significant for yield and vegetative parameters, the mean of yearly values for each of the two harvests and irrigation levels are discussed (Fig. 2).

The plants of the second cut were significantly higher than those of the same treatments of the first (Fig. 2a). In each harvest a significant increase in plant height with the rise in irrigation was recorded. The maximum height of $0.56 \mathrm{~m}$ was obtained by treatment T100 in the second growth period. This was slightly higher than the data reported by Megeji et al. (2005) who measured an average plant height of 0.45 $\mathrm{m}$ in an experiment conducted in India at an altitude of $1300 \mathrm{~m}$ above sea level.

Leaf area index (LAI) data showed the same trend as plant height (Fig. 2b). The maximum LAI (4) was detected in the more irrigated treatment. Fronza and Folegatti (2003) measured values of 4.83 in well-watered plants grown in a lysimeter. Plant and leaf dry weight showed higher values at the second cut (Fig. 2c and $2 \mathrm{~d}$ ). In both cuts the most irrigated treatment (T100) obtained the highest dry matter production in terms of leaves and total dry matter accumulation. Differences among irrigation 

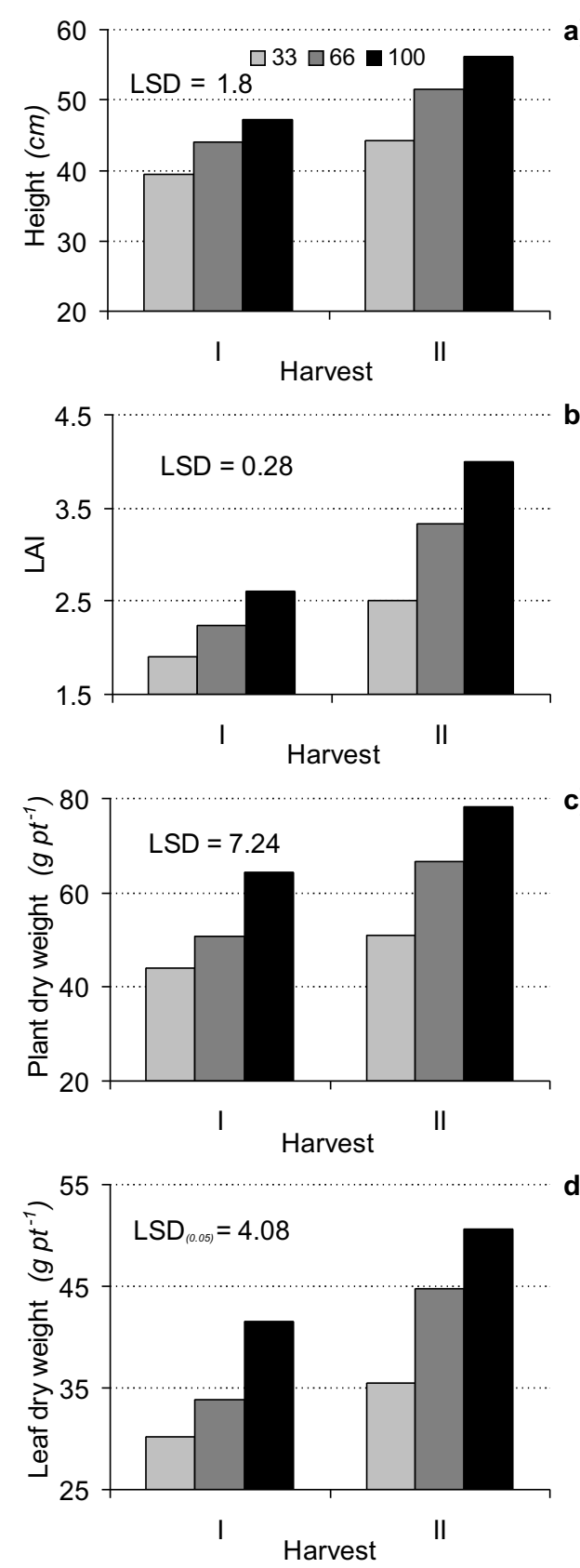

Figure 2. Mean height (a), leaf area index (LAI) (b), plant dry weight (c) and leaf dry weight (d) for each harvest and irrigation treatment (T33,T66 and T100) for the two experimental years. The Least Significant Difference (LSD) of the harvest $\mathrm{x}$ treatment interaction at the 0.05 probability level is also reported.

treatments were always significant in the second growth period, while in the two deficit irrigation treatments of the first period, little improvement of T66 over T33 was observed. This was due to the high soil water content of the first growing periods of both years caused by early spring precipitation, which caused the lack of differences between the two treatments. The higher biomass yield in the second growth period was due to the better conditions in terms of temperature during that period and to the effect of previous irrigation treatments. Therefore the most watered plants at the beginning of the second period already presented a higher number of secondary stems and probably a more developed root system.

Dry leaf yield per hectare obtained as a yearly average was $4.6,3.9$ and $3.3 \mathrm{t} \mathrm{ha}^{-1}$ for treatments T100, T66 and T33, respectively. Yield was higher than the data reported by Megeji et al. (2005) who recorded a leaf dry weight of $1.8 \mathrm{t}$ $\mathrm{ha}^{-1}$ for the September harvest followed by 1.4 $\mathrm{t} \mathrm{ha}^{-1}$ harvested in January.

Andolfi et al. (2006) found that the highest quantity of leaf dry matter produced was approximately $3.6 \mathrm{t} \mathrm{ha}^{-1}$ for the most productive genotype in the first year; it remained nearly the same in the second year, and then increased until the $6^{\text {th }}$ year reaching a peak of $6.1 \mathrm{t} \mathrm{ha}^{-1}$. The same authors in another two-year field experiment tested the possibility of performing two cuts per year in relation to two propagation methods (cutting and micropropagation). Results showed that yield was higher for both treatments in the case of the two cuts. In plants grown in microlysimeters, Fronza and Folegatti (2003) obtained a leaf yield of $4.4 \mathrm{tha}^{-1}$ in a single harvest made at the $80^{\text {th }}$ day after sprouting.

The harvest index (HI), calculated as the ratio of dry leaf yield to the total cumulative dry biomass at harvest, showed no differences between the two cuts for the same irrigation treatments (Fig. 3a). In each harvest period HI decreased with the increase in irrigation regime. Differences were significant between T33 and T66, while treatment T100 showed a non-significant increase as compared with T66. The results showed that dry leaf yield decreased with respect to the whole plant biomass produced with the increase in irrigation volume.

Water use efficiency (WUE), calculated as the ratio of dry biomass accumulated and water consumption, decreased when the irrigation amount increased, showing the same behaviour reported for HI (Fig. 3b).

The diterpenic glycoside content of Stevia rebaudiana Bert. showed a greater concentration 


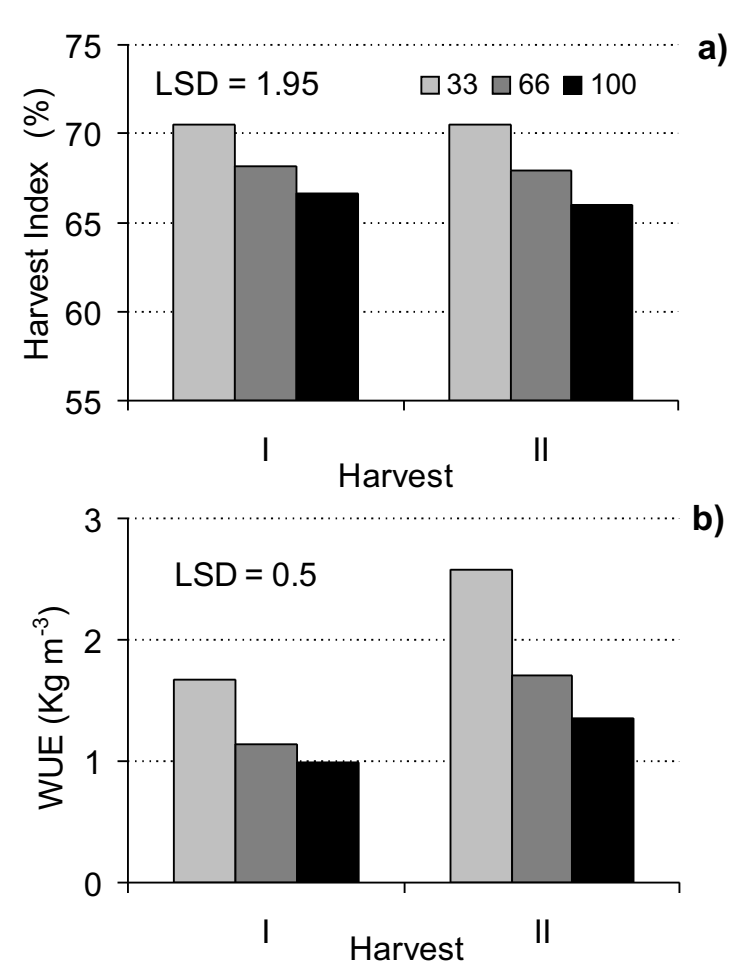

Figure 3. Mean harvest index (HI) (a) and water use efficiency (WUE) (b) for each harvest and irrigation treatment (T33, T66 and T100) for the two experimental years. The Least Significant Difference (LSD) of the harvest $\mathrm{x}$ treatment interaction at the 0.05 probability level is also reported.

of stevioside than that of rebaudioside-A in leaves and stems (Tab. 3). As reported by many authors (i.e. Bondarev et al., 2003/2004), in the present experiment the greatest content of sweetener substances was found in the leaves. Statistical analysis showed no significant interactions as well as the main effects determined by irrigation regimes, time of harvest and years, proving that genetic factors controlled these quality characteristics. This behaviour could be explained since samples were taken in the same plant phenological phase in both years at each harvest time. Given the lack of difference in the

Table 3. Main glycoside content in leaf and stem extracts. Standard deviation is reported in brackets.

\begin{tabular}{lcc}
\hline & $\begin{array}{c}\text { Stevioside } \\
\%(\mathrm{w} / \mathrm{w})\end{array}$ & $\begin{array}{c}\text { Rebaudioside A } \\
\%(\mathrm{w} / \mathrm{w})\end{array}$ \\
\hline Leaves & $8.36( \pm 0.53)$ & $5.72( \pm 0.27)$ \\
Stems & $0.48( \pm 0.02)$ & $0.36( \pm 0.01)$ \\
\hline
\end{tabular}

Table 4. Elements content in dried leaf extract. Standard deviation is reported in brackets.

\begin{tabular}{lc}
\hline Elements & Concentrations \\
\hline Cobalt & ppm \\
Manganese & $0.028( \pm 0.004)$ \\
Iron & $3.22( \pm 0.095)$ \\
Chromium & $307( \pm 2.00)$ \\
Magnesium & $1.66( \pm 0.066)$ \\
Sodium & $4568( \pm 84.0)$ \\
Calcium & $1516( \pm 51.4)$ \\
Potassium & $13457( \pm 885)$ \\
\hline
\end{tabular}

glycoside content, the production of sweeteners increased according to the increase in dry leaf yield with irrigation levels. Overall, glycoside total yield for each year was higher in treatment T100 (0.26 and $0.38 \mathrm{t} \mathrm{ha}^{-1}$ of rebaudioside A and stevioside, respectively), while T66 and T33 showed a rebaudioside production of 0.22 and $0.19 \mathrm{t} \mathrm{ha}^{-1}$ and a stevioside production of 0.33 and 0.28 , respectively.

The glycoside contents of the present experiment are in agreement with those reported by Midmore and Rank (2002) in the native area of the species and with those reported in other environments. Fronza and Folegatti (2003) recorded a value of $6.49 \%$ for stevioside content in a crop grown in a microlysimeter. Megeji et al. (2005) found a stevioside content in the leaves ranging from 3.17 to $9.94 \%$ and from 1.54 to $3.85 \%$ in stems, while no information was reported on rebaudioside A. Starrat et al. (2002) analysed stevia samples from different world cultivation areas showing data of stevioside content ranging between 4 and $20 \%$ on leaf dry weight basis, depending on the cultivar and growing conditions. Kovylyaeva et al. (2007) and Makapugay et al. (1984) reported levels of stevioside ranging from a minimum of $4.6 \%(\mathrm{w} / \mathrm{w}$ of dried leaf) in Paraguay to a maximum of $15.5 \%$ in Viet Nam, while rebaudioside A ranged from $0.3 \%$ in Canada to $3.8 \%$ in Viet Nam and Paraguay.

Irrigation levels and the timing of harvest did not influence the main cation content of the dried leaves (Tab. 3). The values are similar to those reported by Tadhani and Subhash (2006), highlighting the important characteristics of stevia for human health. High concentrations of nutritionally important potassium calcium, magnesium and sodium were found in the leaves. 
Some of these elements play an important role in normal glucose-tolerance. Manganese is an antioxidant micro-nutrient and its presence is useful to prevent free radical mediated diseases, while iron is useful in maintenance of normal haemoglobin levels in the body (Tadhani and Subhash, 2006). The data confirm the role of stevia extracts to protect, regulate and maintain various metabolic processes.

\section{Conclusions}

Besides the evident positive effect of irrigation on plant growth and production, the results of our work confirm that this species is adaptable to the climatic environment of the study area. Proper irrigation scheduling is fundamental to achieve good results as reported by many authors. In this work the cumulated yield of the two harvests of the well-irrigated treatment was $40 \%$ higher than treatment T33, while T66 showed intermediate values. Despite this, WUE and HI decreased when the seasonal irrigation amount increased, since water consumption of T66 and T33 compared with the control (T100) was proportional to the irrigation water supplied, but the increase in yield was not sufficiently high. When water is a limiting factor or its cost is too high, it is possible to reduce watering volume and hence increase water efficiency, but economic feasibility must be calculated.

The vegetative development, yield performance and quality of yield in terms of sweetener substances produced give, to this species, the potential to be successfully cropped. Crop management results indicate that at least two harvests per year could be achieved. Further investigation is needed to assess the economic duration of this crop in the field, since in the same experiments conducted in central-north Italy good yield was achieved for up to eight years, while in the present field work after the harvest of the second year root diseases were observed in winter and many dead plants were counted, probably caused by the high soil water retention at the experimental site.

In order to develop the open field cultivation of this species, further field experiments (plant duration, yield potential, etc.) are required to draw up a cultivation protocol as well as a genetic improvement program to develop varieties that better respond to local environments.

\section{Acknowledgements}

The EU supported this research within the project "Analisi e valutazione di ordinamenti produttivi alternativi nelle aree a riconversione del tabacco" Co.Al.Ta. 2. Thanks are due to Giovanni Romano for his invaluable field work.

\section{References}

Akashi H., Yokoyama Y. 1975. Dried leaf extracts of Stevia. Toxicological test. Shokuhin Kogyo, 18,20:34-43.

Andolfi L., Ceccarini L., Macchia M. 2002. Caratteristiche bioagronomiche di Stevia rebaudiana. L'Informatore Agrario, 23:48-51.

Andolfi L., Macchia M., Ceccarini L. 2006. Agronomicproductive characteristics of two genotype of Stevia rebaudiana in central Italy. Ital. J. Agron., 2:257-262.

Bettinelli M., Spezia S., Bizzarri G. 1996. Trace Element Determination in Lichens by ICP-MS. Atomic Spectroscopy, 17,3:133-141.

Bondarev N.I, Sukhanova M.A., Reshetnyak O.V., Nosov A.M. 2003/2004. Steviol glycoside content in different organs of Stevia rebaudiana and its dynamics during ontogeny. Biologia Plantarium, 47,2:261-264.

Brandle J.E., Starratt A.N., Gijzen M. 1992. Stevia rebaudiana. Its biological, chemical and agricultural properties. Journal of the Science of Food and Agriculture, 59,3:277-281.

Fronza D., Folegatti M.V. 2003. Water consumption of the Estevia (Stevia rebaudiana (Bert.) Bertoni) crop estimated through microlysimeter. Scientia Agricola, 60,3:595-599.

Goettemoeller J., Ching A. 1999. Seed Germination in Stevia rebaudiana. In: Janick J. (ed.): Perspectives on new crops and new uses, 510-511. ASHS Press, Alexandria, VA.

Gonzales R.E. 2000. Necesidad de agua para el cultivo de KA'A HE'E (Stevia rebaudiana Bertoni) bajo riego por goteo, calculado sobre la base de lectura de microlisimetro. San Lorenzo: Universidad Nactional de Asuncion, Faculdad de Ciencias Agrarias. 37 p. Monografia (Graduacion).

Jeppesen P.B, Gregersen S., Poulsen C.R., Hermansen K. 2000. Stevioside acts directly on pancreatic beta cells to secrete insulin: actions independent of cyclic adenosine monophosphate and adenosine triphosphate-sensitive K+-channel activity. Metabolism, 49,2:208-214.

Kinghorn D.A., Soejarto D.D. 1991. Stevioside. Economic and Medical Plant Research. Academic Press, $7: 157-171$. 
Kovylyaeva G.I., Bakaleinik G.A., Strobykina I. Yu., Gubskaya V.I., Sharipova R.R., Al'fonsov V.A., Kataev V.E., Tolstikov A.G. 2007. Glycosides from Stevia rebaudiana. Chemistry of Natural Compounds, 43,1:81-85.

Kolb N., Herrera J.L., Ferreyra D.J., Uliana R.F. 2001. Analysis of Sweet Diterpene Glycosides from Stevia rebaudiana: improved HPLC method. J. Agric. Food Chem., 49:4538-4541.

Makapugay H.C., Nanayakkara N.P.D., Kinghorn A.D. 1984. Improved high-performance liquid chromatographic separation of the Stevia rebaudiana sweet diterpene glycosides using linear gradient elution. Journal of Chromatography, 283:390-395.

Megeji N.W., Kumar J.K., Virendra Singh, Kaul V.K., Ahuja P.S. 2005. Introducing Stevia rebaudiana, a natural zero-calorie sweetener. Current Science, 88, 5:801-804.

Midmore D.J., Rank A.H. 2002. A new rural industry Stevia - to replace imported chemical sweeteners. Report for the Rural Industries Research and Development Corporation 02/022, 55 p.
Oliveira-Filho R.M., Valle L.B.S., Minetti C.A.S.A., Uchara O.A. 1986. Evaluation of the effects of raw Stevia rebaudiana extract in the endocrinous sphere; study on rats. Third Brazilian Seminar on Stevia rebaudiana Bertoni, July, p. 20.

Soejarto D.D., Kinghorn A.D., Farnsworth N.R. 1982. Potential sweetening agents of plant origin. III. Organoleptic evaluation of stevia leaf herbarium samples for sweetness. J. Nat. Prod., 45:590-599.

Starratt A.N., Kirby C.W., Pocs R., Brandle J.E. 2002. Rebaudioside F, a diterpene glycoside from Stevia rebaudiana. Phytochemistry, 59:367-370.

Tadhani M., Subhash R. 2006. Preliminary studies on Stevia rebaudiana leaves: proximal composition, mineral analysis and phytochemical screening. J. Med. Sci., 6,3:321-326.

Zaidan L.B.P., Dietrich S.M.C., Felippe G.M. 1980. Effect of photoperiod on flowering and stevioside content in plants of Stevia rebaudiana Bertoni. Jap. J. Crop Sci., 49:569-574. 